\title{
DETERMINAÇÃO SIMULTÂNEA DE TRIALOMETANOS E AGROTÓXICOS EM ÁGUA POR CROMATOGRAFIA GASOSA
}

\author{
Elenice A. Carlos, Antônio A. Neves, César Reis e Maria Eliana L. R. de Queiroz* \\ Departamento de Química, Universidade Federal de Viçosa, Campus Universitário, s/n, 36570-000 Viçosa - MG, Brasil
}

Recebido em 4/5/10; aceito em 31/8/10; publicado na web em 30/11/10

\begin{abstract}
DETERMINATION OF TRIHALOMETHANES AND PESTICIDES IN WATER BY GAS CHROMATOGRAPHY. A method for simultaneous analysis of trihalomethanes and organochloride and pyrethroid pesticides in water utilizing SPME-HS and GC-ECD was developed. In the optimized method $25 \mathrm{~mL}$ of water containing $2 \%(\mathrm{w} / \mathrm{v}) \mathrm{Na}_{2} \mathrm{HPO}_{4}$ were heated to $60{ }^{\circ} \mathrm{C}$ for $50 \mathrm{~min}$. The fiber (PDMS $-100 \mu \mathrm{m}$ ) was exposed to a headspace for the same period. For all analytes it was found that LOQ $<$ MCL (Maximum Contaminant Level), CV $<20 \%$ and $r>0.9$. The method was applied to potable and surface water samples. Some trihalomethanes were encountered in potable waters, at levels below the MCL.
\end{abstract}

Keywords: SPME; THM; pesticides.

\section{INTRODUÇÃO}

A depreciação da qualidade de águas superficiais e consequente escassez de água adequada para o consumo humano é atualmente uma preocupação de órgãos públicos ambientais e de saúde. Essa depreciação pode ser causada pela presença de substâncias potencialmente tóxicas como metais pesados, compostos nitrogenados, fenóis, trialometanos, BTX (benzeno, tolueno e xileno), agrotóxicos, dentre outras. ${ }^{1,2}$

Os agrotóxicos organoclorados destacam-se entre os principais agentes contaminantes por apresentarem elevada persistência ambiental. Esses compostos foram intensamente empregados no combate a insetos transmissores de doenças fatais como malária e febre amarela e, também, no controle de pragas que afetavam a produção agrícola. ${ }^{3}$ Devido ao potencial tóxico e por serem bioacumulativos e persistentes no meio ambiente, os organoclorados tiveram seu uso restrito ou suprimido em muitos países. ${ }^{4}$ No Brasil, a comercialização, o uso e a distribuição de alguns agrotóxicos organoclorados destinados à agropecuária foram proibidos em 1985 pela Portaria 329 do Ministério da Agricultura. ${ }^{5}$ Esta medida não eliminou completamente o emprego desses compostos no Brasil, uma vez que permitia a utilização de alguns organoclorados em iscas formicidas (aldrin e dodecacloro), em campanhas de saúde pública e na agricultura em caráter emergencial. ${ }^{5}$ A partir de 14/5/2009 uma medida mais rigorosa foi adotada para o DDT pela sanção da Lei $\mathrm{N}^{\circ} 11.936$ que proíbe a fabricação, importação, exportação, manutenção em estoque, comercialização e o uso do DDT em todo o território nacional. ${ }^{6}$

Para substituir os compostos organoclorados foram introduzidos novos produtos no mercado. Dentre esses se destacam os piretroides, que vêm sendo amplamente empregados em atividades agropecuárias, em formulações de uso doméstico e em campanhas de saúde pública, para o controle de vetores de doenças. ${ }^{7}$ Esses compostos apresentam a vantagem de serem praticamente atóxicos para mamíferos, quando comparados a outros inseticidas, além do baixo efeito residual. ${ }^{8}$

A intensa utilização dos agrotóxicos, o seu potencial tóxico, a persistência no ambiente e acumulação nas cadeias alimentares

\footnotetext{
*e-mail: meliana@ufv.br
}

mostram a necessidade do monitoramento de resíduos em alimentos e em matrizes ambientais. Atenção especial deve ser dada à água potável, pois o consumo diário de água contaminada com resíduos de agrotóxicos pode causar efeitos tóxicos, como câncer e danos no sistema nervoso central, dependendo do tipo de composto e da quantidade ingerida. $^{9}$

Tendo em vista a possibilidade de consumo, pela população, de água contaminada, órgãos como WHO (World Health Organization), EPA (Environmental Protection Agency, USA) e Ministério da Saúde, no Brasil, estabeleceram limites máximos permitidos (LMP) para agrotóxicos em águas destinadas ao consumo humano.

No Brasil, o padrão de potabilidade para substâncias químicas que representam riscos à saúde humana é estabelecido pela Portaria 518 do Ministério da Saúde, de 25/3/2004. Nessa Portaria a maioria dos agrotóxicos listados pertence à classe dos organoclorados. Os LMP, para esse grupo de agrotóxicos, variam entre $0,03 \mu \mathrm{g} \mathrm{L}^{-1}$ (aldrin, dieldrin, heptacloro e heptacloro epóxido) e $20 \mu \mathrm{g} \mathrm{L} \mathrm{L}^{-1}$ (alaclor, endossulfam e metoxicloro). Outro agrotóxico presente nesta lista com um LMP de $20 \mu \mathrm{g} \mathrm{L} \mathrm{L}^{-1}$ é a permetrina, pertencente ao grupo dos piretroides. Atualmente este é o único piretroide presente nesta lista, apesar do amplo espectro de atuação dessa classe de compostos. ${ }^{1}$

Além dos agrotóxicos, os trialometanos também são monitorados pelos órgãos nacionais e internacionais que estabelecem os padrões de potabilidade. Trialometanos (THMs) são subprodutos de desinfecção formados na etapa de cloração da água. Esses compostos podem representar risco à saúde humana, pois são considerados possivelmente cancerígenos. ${ }^{9,10}$ O LMP adotado pela Portaria 518 para THM total é de $100 \mu \mathrm{g} \mathrm{L}^{-1}$, que corresponde à soma das concentrações dos quatro principais compostos, clorofórmio, bromodiclorometano, dibromoclorometano e bromofórmio. ${ }^{1}$

A avaliação da qualidade de águas para consumo humano relativa à presença de agrotóxicos, trialometanos e outros compostos orgânicos pode ser feita empregando técnicas cromatográficas, especialmente a cromatografia gasosa. ${ }^{11-13}$ Por esta técnica as substâncias são separadas, identificadas e quantificadas, sendo necessária, entretanto, etapa prévia de extração e concentração.

A microextração em fase sólida (MEFS) é uma das técnicas de extração mais empregada atualmente, principalmente quando se trata 
de extração multirresíduo de compostos orgânicos em amostras de água. Estudos reportados na literatura têm mostrado a eficiência desta técnica para extração de trialometanos, ${ }^{11}$ piretroides, ${ }^{12,13}$ organoclorados, ${ }^{14}$ além de propostas de extração simultânea de agrotóxicos pertencentes a diferentes classes. ${ }^{15,16}$ Os métodos de análise multirresíduo apresentados na literatura associam diferentes classes de agrotóxicos, porém, não sugerem a associação de agrotóxicos e trialometanos em um único método. Além disso, os métodos propostos para extração de piretroides sugerem que a MEFS seja realizada por imersão da fibra na amostra (modo direto). ${ }^{12,13,15-17}$

O objetivo principal desse trabalho foi desenvolver e validar um método para análise simultânea dos trialometanos, clorofórmio, bromodiclorometano, dibromoclorometano e bromofórmio; dos agrotóxicos organoclorados, aldrin, DDT, dieldrin, endossulfam, endrin, lindano, heptacloro, hexaclorobenzeno e pentaclorofenol; e dos piretroides, $\lambda$-cialotrina, cipermetrina, deltametrina e permetrina em águas. As técnicas de MEFS, por headspace (HS), e cromatografia gasosa (CG), com um detector por captura de elétrons (DCE), foram empregadas para extração e quantificação dos analitos de interesse.

\section{PARTE EXPERIMENTAL}

\section{Reagentes e soluções}

Todos os reagentes usados foram de grau analítico. As soluções estoque de piretroides foram preparadas a partir de padrões de $\lambda$-cialotrina ( pureza $=86,5 \%)$ e permetrina $($ pureza $=92,2 \%)$ obtidos da Syngenta, Ltd. (Bracknell, Berkshine, UK), de cipermetrina (pure$\mathrm{za}=92,4 \%$ ) obtido da Chem Service, Inc. (West Chester, PA, USA) e de deltametrina (pureza $=98 \%$ ) obtido da Sigma-Aldrich (Seelze, Alemanha), em acetonitrila (Tedia/HPLC-Spectro). As soluções estoque de organoclorados foram preparadas em metanol (Merck/ PA) a partir de padrões de aldrin (pureza $=98,5 \%)$, DDT (pureza $=$ $98,8 \%)$, heptacloro $($ pureza $=99,5 \%)$ e pentaclorofenol $($ pureza $=$ 99,6\%) obtidos da Supelco, Inc. (Bellefort, PA, USA) e padrões de dieldrin (pureza $=97,9 \%)$, endossulfam $($ pureza $=91,5 \%)$, endrin $($ pureza $=99,3 \%)$, lindano $($ pureza $=99,8 \%)$ e hexaclorobenzeno ( pureza $=99,8 \%$ ) obtidos da Sigma-Aldrich (Seelze, Alemanha).

A partir das soluções estoque individuais, foram preparadas uma solução estoque contendo os 4 piretroides em acetonitrila e uma solução estoque contendo os 9 organoclorados em metanol. Uma solução estoque de trialometanos, em metanol (Merck/PA), foi preparada a partir de uma mistura padrão obtida da Supelco, Inc. (Bellefort, PA, USA), em metanol, contendo clorofórmio, bromodiclorometano, dibromoclorometano e bromofórmio na concentração de $2000 \mu \mathrm{g} \mathrm{mL}^{-1}$. Estas soluções foram estocadas a $-18^{\circ} \mathrm{C}$. A partir das soluções estoque foram preparadas as soluções de trabalho nas concentrações adequadas.

\section{Amostras}

Nas etapas de otimização e validação do método foi utilizada água Milli-Q.

O método otimizado foi aplicado em amostras de água tratada, que foram coletadas em 4 pontos da rede de distribuição e no reservatório da estação de tratamento de água (ETA) que abastece a cidade de Viçosa, MG. Foram também coletadas amostras em 2 pontos do Ribeirão São Bartolomeu, no local de captação de água da ETA e a jusante da cidade de Viçosa, MG. As amostras foram coletadas em frascos de vidro de $44 \mathrm{~mL}$ equipados com tampa de teflon e septo de silicone, contendo $3 \mathrm{mg}$ de sulfito de sódio. Os frascos foram totalmente preenchidos com as amostras evitando a formação de bolhas e mantidos sob refrigeração, a $4{ }^{\circ} \mathrm{C}$. A extração e análise cromatográfica foram realizadas no mesmo dia da coleta.

\section{MEFS-HS}

Os ensaios de otimização da técnica para determinação simultânea de trialometanos e agrotóxicos organoclorados e piretroides por MEFS-HS foram realizados empregando-se um suporte (holder) manual para MEFS (Supelco, Bellefort, USA) equipado com fibra de polidimetilsiloxano (PDMS) de $100 \mu \mathrm{m}$ de espessura (Supelco, Bellefort, USA).

Amostras de 25,0 mL de água fortificadas com os 17 analitos de interesse a uma concentração de $40 \mu \mathrm{g} \mathrm{L}^{-1}$ foram colocadas em frascos de vidro de $44 \mathrm{~mL}$ de capacidade, equipados com tampa de teflon e septo de silicone. Os frascos contendo as amostras foram transferidos para um banho termostatizado, a uma temperatura fixa, previamente ajustada. A fibra foi colocada em contato com a parte gasosa da amostra (headspace) durante todo o período de aquecimento. Após extração, a fibra foi retirada do frasco e introduzida no injetor do cromatógrafo a gás. Os analitos foram termicamente dessorvidos da fibra, durante $10 \mathrm{~min}$, sob fluxo do gás de arraste e carreados para a coluna cromatográfica.

Para estabelecer as melhores condições de extração dos analitos em água, foram avaliados a adição de sal $\left(0\right.$ e $2 \%$ m/v de $\left.\mathrm{Na}_{2} \mathrm{HPO}_{4}\right)$, a temperatura do banho termostatizado $\left(40\right.$ e $\left.60{ }^{\circ} \mathrm{C}\right)$ e o tempo de aquecimento (30 e $50 \mathrm{~min}$ ). As melhores condições de extração foram avaliadas comparando os valores de áreas dos picos referentes aos analitos de interesse em cada ensaio.

\section{Análises cromatográficas}

Para determinação simultânea dos trialometanos e dos agrotóxicos organoclorados e piretroides foi empregado um cromatógrafo a gás Shimadzu, modelo 2014, com detector por captura de elétrons. As separações foram realizadas em uma coluna capilar Rtx-5MS, Restek (30 m x 0,25 mm d.i. e 0,25 $\mu \mathrm{m}$ de espessura de filme). As condições cromatográficas de análise foram: temperatura do injetor $250{ }^{\circ} \mathrm{C}$, temperatura do forno da coluna $40^{\circ} \mathrm{C}(2 \mathrm{~min})$, com rampa de aquecimento de $20^{\circ} \mathrm{C} / \mathrm{min}$ até $200{ }^{\circ} \mathrm{C}$, seguida de rampa de $4{ }^{\circ} \mathrm{C} /$ min até $290{ }^{\circ} \mathrm{C}$, sendo esta temperatura mantida por 2 min e temperatura do detector de $300{ }^{\circ} \mathrm{C}$; vazão do gás de arraste $\left(\mathrm{N}_{2}\right)$ de 1,2 $\mathrm{mL} \min ^{-1}$ e divisão de fluxo (split) de 1:5. A fibra ficou exposta no injetor por $10 \mathrm{~min}$.

Para as análises por cromatografia gasosa com detecção por espectrometria de massas (CG-EM) utilizou-se um equipamento da Shimadzu, modelo GC-2010, com uma coluna Rtx-5MS, Restek ( $30 \mathrm{~m} \times 0,25 \mathrm{~mm}$ d.i. e $0,25 \mu \mathrm{m}$ de espessura de filme). O injetor foi mantido a $250{ }^{\circ} \mathrm{C}$, com a razão de divisão de fluxo (split) de 1:5. A temperatura do forno da coluna foi mantida a $40{ }^{\circ} \mathrm{C}$ por $2 \mathrm{~min}$, seguida de rampas de aquecimento de $20{ }^{\circ} \mathrm{C} / \mathrm{min}$ até $200{ }^{\circ} \mathrm{C}$ e de $4{ }^{\circ} \mathrm{C} / \mathrm{min}$ até $290^{\circ} \mathrm{C}$, sendo esta temperatura mantida por $2 \mathrm{~min}$. O gás hélio foi utilizado como gás de arraste empregando uma vazão de 1,2 mL $\mathrm{min}^{-1}$. A fibra ficou exposta ao injetor durante $10 \mathrm{~min}$.

Para a detecção por espectrometria de massas utilizou-se um detector contendo uma fonte de ionização por elétrons (EI-70 eV) e um analisador de massas quadrupolo, operado no modo varredura linear (scan) $40-500 \mathrm{~m} / \mathrm{z}$ para identificação dos compostos. A interface foi mantida a $310{ }^{\circ} \mathrm{C}$ e a fonte de íons a $200{ }^{\circ} \mathrm{C}$.

\section{Validação}

O método foi validado baseando-se nas recomendações do Instituto Nacional de Metrologia, Normalização e Qualidade Industrial (INMETRO), ${ }^{18}$ Agência Nacional de Vigilância Sanitária (ANVISA), ${ }^{19}$ Agência Reguladora dos Estados Unidos (FDA) ${ }^{20}$ e Conferência Internacional em Harmonização (ICH), ${ }^{21}$ que estabelecem critérios de 
validação de métodos analíticos. Os parâmetros analíticos avaliados foram: precisão, linearidade, faixa de trabalho, seletividade e limites de detecção e de quantificação.

O método validado foi empregado para a determinação dos 17 compostos em amostras de água destinada ao consumo humano e água superficial do município de Viçosa, MG.

\section{RESULTADOS E DISCUSSÃO}

\section{Análise cromatográfica}

As condições cromatográficas otimizadas para análise simultânea dos 17 compostos permitiram a completa separação de todos os analitos com um tempo de análise de 35 min. Na Figura 1 está representado um cromatograma obtido após análise de água Milli-Q fortificada com os trialometanos, organoclorados e piretroides em concentrações iguais a 60,2 e $100 \mu \mathrm{g} \mathrm{L}^{-1}$, respectivamente. Na Tabela 1 estão os nomes, as estruturas químicas e os tempos de retenção dos compostos.

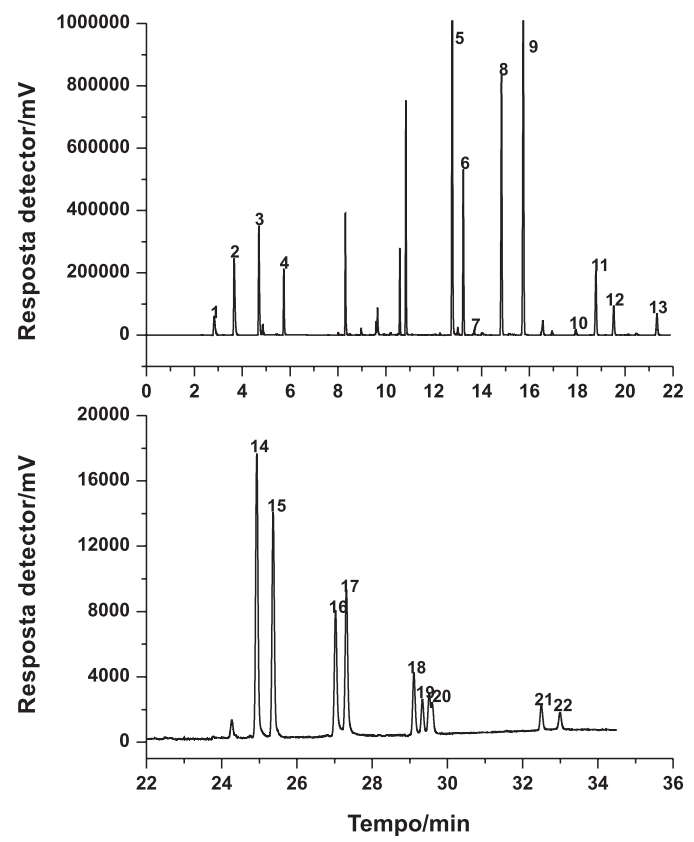

Figura 1. Cromatograma obtido da análise de água Milli-Q fortificada com os trialometanos, organoclorados e piretroides em concentrações iguais a 60 , 2 e $100 \mu \mathrm{g} \mathrm{L} \mathrm{L}^{-1}$, respectivamente, onde: (1) clorofórmio; (2) bromodiclorometano; (3) dibromoclorometano; (4) bromofórmio; (5) hexaclorobenzeno; (6) lindano; (7) pentaclorofenol; (8) heptacloro; (9) aldrin; (10) endossulfam; (11) dieldrin; (12) endrin; (13) DDT; (14) e (15) $\lambda$-cialotrina; (16) e (17) permetrina; (18), (19) e (20) cipermetrina; (21) e (22) deltametrina

\section{Otimização da MEFS-HS}

A extração de trialometanos e agrotóxicos em amostras de água pode ser feita empregando-se a microextração em fase sólida pelo modo indireto, ${ }^{11,22}$ mantendo a fibra em contato com o espaço vazio acima da matriz (headspace) ou pelo modo direto, ${ }^{12,16}$ mantendo a fibra em contato com a matriz. Este modo é o mais utilizado para a extração de compostos de baixa volatilidade, como os piretroides. Entretanto, apresenta a desvantagem de expor a fibra a constituintes da matriz que poderiam danificar a fibra ou ficarem adsorvidos fortemente à mesma, exigindo etapa adicional de limpeza da fibra. ${ }^{23}$ Para aumentar a vida útil da fibra e diminuir o número de etapas operacionais optou-se neste trabalho em empregar o modo indireto.
Os efeitos da temperatura, tempo de extração e adição de $\mathrm{Na}_{2} \mathrm{H}$ $\mathrm{PO}_{4}$ foram avaliados univariadamente. Em cada ensaio os valores de área para os picos referentes a cada um dos analitos foram registrados e as porcentagens de aumento de resposta foram calculadas. Os piretroides apresentaram picos duplos, devido à conversão em isômeros durante a injeção no cromatógrafo. ${ }^{24} \mathrm{O}$ valor da área atribuído a esses analitos foi considerado como sendo o somatório das áreas dos picos dos respectivos isômeros.

As temperaturas a que foram submetidas as amostras foram $40 \mathrm{e}$ $60{ }^{\circ} \mathrm{C}$. Observou-se que na extração a uma temperatura de $40{ }^{\circ} \mathrm{C} \mathrm{du}$ rante 30 min de aquecimento e sem adição de sal, nenhum dos quatro piretroides foi extraído em quantidade suficiente para ser detectado. Quando a extração foi realizada nas mesmas condições aumentandose apenas a temperatura para $60^{\circ} \mathrm{C}$, houve um aumento nas respostas de todos os analitos e foi possível detectar os quatro piretroides em estudo. A influência da temperatura na taxa de extração de compostos foi observada também em outros trabalhos que utilizaram a técnica de MEFS-HS para extração de uma ou mais classes de compostos em amostras de água. ${ }^{11,25}$ Para compostos pouco voláteis, como os organoclorados e piretroides, foram empregadas temperaturas mais elevadas, próximas a $60{ }^{\circ} \mathrm{C} .{ }^{22,26}$

Para avaliar a influência da adição de $\mathrm{Na}_{2} \mathrm{HPO}_{4}$ na extração dos analitos foram empregados tempo e temperatura de extração iguais a 30 min e $60{ }^{\circ} \mathrm{C}$, respectivamente. Os níveis avaliados foram de 0 e $2 \%(\mathrm{~m} / \mathrm{v})$ de $\mathrm{Na}_{2} \mathrm{HPO}_{4}$. Com a adição de sal não foram observadas alterações significativas, ao nível de $95 \%$ de confiança pelo teste $\mathrm{t}$ de Student, nas respostas cromatográficas da maioria dos trialometanos e organoclorados. Foram observadas reduções nas respostas do bromofórmio e do hexaclorobenzeno de 6 e $21 \%$, respectivamente, e aumentos nas áreas dos picos da $\lambda$-cialotrina, permetrina, cipermetrina e deltametrina de $81,102,12$ e $29 \%$, respectivamente. Aumentos na taxa de extração de piretroides em função do aumento da força iônica da solução aquosa foram observados também por outros pesquisadores. ${ }^{27,28}$ Considerando a maior facilidade de transferência dos trialometanos e organoclorados para a fase gasosa, devido à maior volatilidade desses em relação aos piretroides, e considerando o aumento expressivo nas respostas da $\lambda$-cialotrina e permetrina pela adição do sal, foi adotada a adição de $\mathrm{Na}_{2} \mathrm{HPO}_{4}$ no procedimento de extração simultânea dos analitos.

$\mathrm{O}$ efeito do tempo de exposição da fibra foi avaliado a 30 e 50 min, empregando $2 \%(\mathrm{~m} / \mathrm{v})$ de $\mathrm{Na}_{2} \mathrm{HPO}_{4}$ e temperatura de extração de $60{ }^{\circ} \mathrm{C}$. Observou-se aumento nas respostas de todos os analitos, quando o tempo de extração foi aumentado de 30 para $50 \mathrm{~min}$, principalmente para os piretroides. Para esses compostos foi observado um aumento de 65, 83, 95 e $112 \%$ nas respostas da $\lambda$-cialotrina, permetrina, cipermetrina e deltametrina, respectivamente. Tempos de extração superiores a 50 min aumentavam as respostas dos analitos significativamente, indicando que o sistema ainda não havia alcançado o equilíbrio. No entanto, para sincronizar o tempo de extração com o tempo necessário para análise e condicionamento do cromatógrafo a gás entre as injeções foi adotado o tempo de 50 min, ou seja, optouse por trabalhar fora do equilíbrio mantendo todas as condições de extração constantes durante as extrações de padrões e amostras, para evitar a interferência da componente cinética nos resultados. A escolha deste tempo permitiu aumentar a frequência analítica e viabilizar a aplicação do método em análises de rotina.

O método desenvolvido para determinação simultânea de trialometanos e agrotóxicos organoclorados e piretroides em água consiste em transferir 25,0 $\mathrm{mL}$ de amostra de água para um frasco de vidro de $44 \mathrm{~mL}$ de capacidade, equipado com tampa de teflon e septo de silicone, contendo $0,500 \mathrm{~g}$ de $\mathrm{Na}_{2} \mathrm{HPO}_{4}$. O sistema é aquecido a uma temperatura constante de $60{ }^{\circ} \mathrm{C}$ por $50 \mathrm{~min}$. A fibra PDMS de $100 \mu \mathrm{m}$ fica exposta no espaço vazio do frasco (headspace) durante 
Tabela 1. Tempos de retenção e estruturas químicas dos compostos

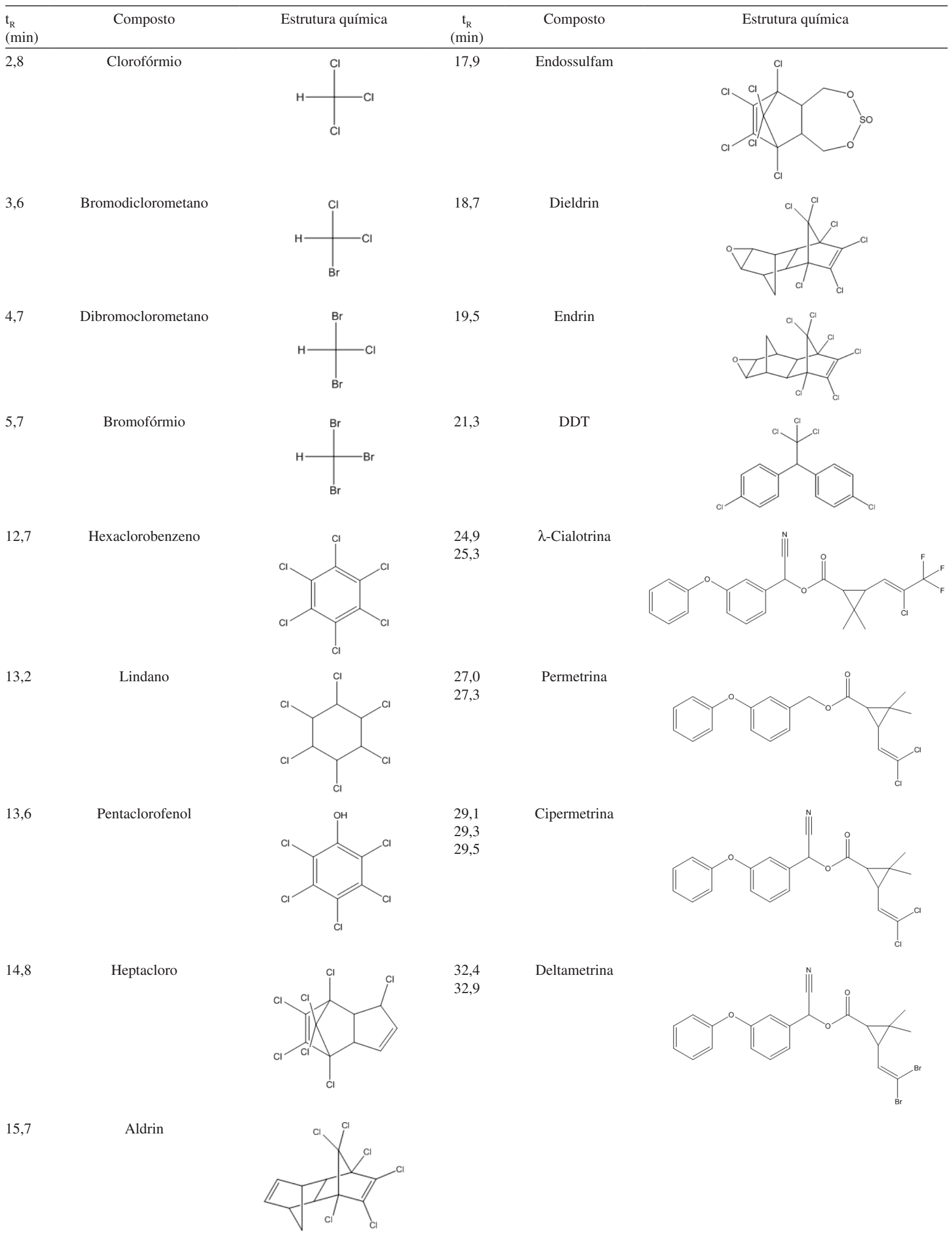


todo o período de aquecimento. Após extração, a fibra é retirada e introduzida no injetor do cromatógrafo a gás, sendo exposta durante 10 min. Os analitos são termicamente dessorvidos sob fluxo do gás de arraste e carreados para a coluna cromatográfica.

Para determinação do tempo de dessorção foi feito um estudo prévio verificando que $10 \mathrm{~min}$ de exposição da fibra no injetor foram suficientes para dessorção completa dos analitos. Trabalhos reportados na literatura empregaram tempos de dessorção semelhantes a este para compostos da classe dos organoclorados ${ }^{29}$ e piretroides. ${ }^{12}$

\section{Validação}

Para avaliar a seletividade, o método otimizado foi aplicado em amostras de água superficial. Posteriormente, essas amostras foram fortificadas com os 17 princípios ativos estudados e submetidas novamente ao método de extração e análise. Os cromatogramas referentes a essas amostras foram comparados, não sendo observado nenhum interferente com resposta nos tempos de retenção dos analitos de interesse.

Os limites de detecção (LD) e de quantificação do método (LQ) foram determinados pela razão sinal/ruído. Amostras de água fortificadas com os analitos de interesse, em concentrações decrescentes, foram submetidas ao procedimento de extração e quantificação. Foram empregadas concentrações entre 1,0 e $0,01 \mu \mathrm{g} \mathrm{L}^{-1}$ para os trialometanos, entre $1,0 \mathrm{e} 0,001 \mu \mathrm{g} \mathrm{L}^{-1}$ para os organoclorados e entre 30 e $0,1 \mu \mathrm{g} \mathrm{L}^{-1}$ para os piretroides. Foi considerado como LD e LQ aquela concentração que produziu um sinal 3 e 10 vezes, respectivamente, superior ao ruído da linha de base. Os dados de LD, LQ e LMP são apresentados na Tabela 2. Vale ressaltar que para os piretroides tomou-se como referência o LMP estabelecido para a permetrina, uma vez que para os demais piretroides os valores guia ainda não foram estabelecidos. Para os trialometanos o LMP se refere à soma das concentrações dos quatro principais trialometanos: clorofórmio, bromodiclorometano, dibromoclorometano e bromofórmio. Os valores de LD apresentados na Tabela 2 são superiores àqueles obtidos por métodos empregados para análise de compostos pertencentes a uma única classe. ${ }^{25,26}$ No entanto, para todos os analitos estudados, os limites de quantificação do método proposto são menores do que os respectivos LMP estabelecidos pela legislação brasileira. ${ }^{1}$ Além disso, o método proposto permite a análise simultânea de vários analitos pertencentes a diferentes classes (trialometanos, organoclorados e piretroides)

Para avaliar a linearidade do método, foram construídas curvas analíticas para os quatro trialometanos estudados, no intervalo entre 0,1 a $100 \mu \mathrm{g} \mathrm{L}{ }^{-1}$. Para os pesticidas organoclorados aldrin, dieldrin, heptacloro, hexaclorobenzeno e lindano foram construídas curvas analíticas no intervalo de 0,01 a $4 \mu \mathrm{g} \mathrm{L}^{-1}$. O intervalo de concentração empregado para o DDT, endrin, endossulfam e pentaclorofenol foi de 0,05 a 4 $\mu \mathrm{g} \mathrm{L}^{-1}$. As curvas analíticas referentes aos piretroides $\lambda$-cialotrina, permetrina e cipermetrina foram construídas no intervalo de 1 a 140 $\mu \mathrm{g} \mathrm{L}^{-1}$. Para a deltametrina foi empregado o intervalo de concentração de 10 a $140 \mu \mathrm{g} \mathrm{L}^{-1}$. Foram empregados sete níveis de concentração e os coeficientes de correlação (r) obtidos foram maiores que 0,95 para todos os analitos estudados, conforme apresentado na Tabela 2.

Para a determinação dos analitos de interesse em águas superficiais e tratadas foram construídas curvas analíticas para cada um

Tabela 2. Resultados de precisão, linearidade, faixa de trabalho, limites de deteç̧ão e quantificação do método e LMP pela legislação

\begin{tabular}{|c|c|c|c|c|c|c|c|c|}
\hline \multirow[t]{2}{*}{ Analito } & \multirow{2}{*}{$\begin{array}{c}\text { Precisão } \\
\text { intermediária } \\
(\mathrm{CV}, \%)^{\mathrm{a}}\end{array}$} & \multicolumn{2}{|c|}{ Linearidade } & \multicolumn{2}{|c|}{ Faixa de trabalho } & \multirow[t]{2}{*}{$\mathrm{LD}\left(\mu \mathrm{g} \mathrm{L}^{-1}\right)$} & \multirow[t]{2}{*}{$\mathrm{LQ}\left(\mu \mathrm{g} \mathrm{L}^{-1}\right)$} & \multirow[t]{2}{*}{$\operatorname{LMP}\left(\mu \mathrm{g} \mathrm{L}^{-1}\right)$} \\
\hline & & Faixa $\left(\mu \mathrm{g} \mathrm{L}^{-1}\right)$ & $\mathrm{r}$ & Faixa $\left(\mu \mathrm{g} \mathrm{L}^{-1}\right)$ & $\mathrm{r}$ & & & \\
\hline \multicolumn{9}{|l|}{ Trialometanos } \\
\hline Bromodiclorometano & 5 & $0,1-100$ & 0,9933 & $0,1-40$ & 0,9995 & 0,03 & 0,1 & $100^{*}$ \\
\hline Bromofórmio & 3 & $0,1-100$ & 0,9806 & $0,1-40$ & 0,9969 & 0,03 & 0,1 & $100^{*}$ \\
\hline Clorofórmio & 9 & $0,1-100$ & 0,9961 & $0,5-60$ & 0,9933 & 0,15 & 0,5 & $100 *$ \\
\hline Dibromoclorometano & 3 & $0,1-100$ & 0,9863 & $0,1-40$ & 0,9986 & 0,03 & 0,1 & $100^{*}$ \\
\hline \multicolumn{9}{|l|}{ Organoclorados } \\
\hline Aldrin & 10 & $0,01-4$ & 0,9959 & $0,01-1$ & 0,9978 & 0,003 & 0,01 & 0,03 \\
\hline DDT & 14 & $0,05-4$ & 0,9917 & $0,1-4$ & 0,9916 & 0,03 & 0,1 & 2 \\
\hline Dieldrin & 9 & $0,01-4$ & 0,9624 & $0,01-1$ & 0,9956 & 0,003 & 0,01 & 0,03 \\
\hline Endossulfam & 19 & $0,05-4$ & 0,9764 & $0,1-4$ & 0,9914 & 0,03 & 0,1 & 20 \\
\hline Endrin & 6 & $0,05-4$ & 0,9541 & $0,05-3$ & 0,9699 & 0,015 & 0,05 & 0,6 \\
\hline Heptacloro & 10 & $0,01-4$ & 0,9968 & $0,01-1$ & 0,9997 & 0,003 & 0,01 & 0,03 \\
\hline Hexaclorobenzeno & 12 & $0,01-4$ & 0,9872 & $0,03-4$ & 0,9910 & 0,009 & 0,03 & 1 \\
\hline Lindano & 3 & $0,01-4$ & 0,9607 & $0,03-1$ & 0,9898 & 0,009 & 0,03 & 2 \\
\hline Pentaclorofenol & 19 & $0,05-4$ & 0,9905 & $0,1-4$ & 0,9959 & 0,03 & 0,1 & 9 \\
\hline \multicolumn{9}{|l|}{ Piretroides } \\
\hline$\lambda$-Cialotrina & 13 & $1-140$ & 0,9937 & $1-80$ & 0,9952 & 0,3 & 1 & --- \\
\hline Cipermetrina & 13 & $1-140$ & 0,9832 & $1-80$ & 0,9956 & 0,3 & 1 & --- \\
\hline Deltametrina & 14 & $10-140$ & 0,9660 & $10-80$ & 0,9858 & 3 & 10 & --- \\
\hline Permetrina & 15 & $1-140$ & 0,9768 & $1-80$ & 0,9943 & 0,3 & 1 & 20 \\
\hline
\end{tabular}

${ }^{a}$ Coeficiente de variação $(n=7) \mathrm{LD}=$ Limite de detecção, $\mathrm{LQ}=$ Limite de quantificação, LMP = Limite máximo permitido pela Portaria 518 do Ministério da Saúde (2004); *Valor referente à soma das concentrações dos quatro trialometanos. 
dos 17 analitos, empregando faixas de trabalho com intervalos de concentração mais restritos. Para tal, foram empregados seis níveis de concentração, dentro da faixa que melhor atendesse aos objetivos do trabalho, sendo o LQ de cada composto o limite inferior da curva analítica. Na Tabela 2 estão apresentados os intervalos de concentração empregados para cada analito. Os valores de coeficientes de correlação (r) obtidos para os analitos de interesse foram maiores que 0,99 , exceto para o endrin, cujo valor de $r$ foi igual a 0,97. Esses valores indicam a boa linearidade de resposta do método para os analitos estudados. ${ }^{17,18}$

A precisão intermediária foi avaliada pelo valor do coeficiente de variação $(\mathrm{CV})$, obtido após análises executadas em 3 dias diferentes, sendo os ensaios realizados a cada 10 dias. Em cada ensaio sete amostras idênticas foram analisadas por um mesmo analista, no mesmo laboratório, sob as mesmas condições de trabalho. Para tal, foram empregadas amostras fortificadas com trialometanos e piretroides a 1 e $10 \mu \mathrm{g} \mathrm{L}^{-1}$, respectivamente; e organoclorados a 0,03 $\mu \mathrm{g} \mathrm{L}^{-1}$, exceto para o DDT, endossulfam e pentaclorofenol, cuja concentração empregada foi de $0,1 \mu \mathrm{g} \mathrm{L}^{-1}$. Os valores de $\mathrm{CV}$ obtidos para a maioria dos compostos são menores que $15 \%$. Os organoclorados pentaclorofenol e endossulfam apresentaram CV iguais a 19\% (Tabela 2). Para esses compostos a concentração de fortificação das amostras submetidas aos ensaios de precisão intermediária foi igual aos limites de quantificação dos mesmos $\left(0,1 \mu \mathrm{g} \mathrm{L}^{-1}\right)$. Estes resultados estão de acordo com os critérios adotados pela Agência dos Estados Unidos que regula sobre alimentos e drogas (Food and Drug Administration), que recomenda que os resultados de CV não devem exceder a $15 \%$, exceto para o limite de quantificação, o qual não deve exceder $20 \%{ }^{19}$

\section{Análise de amostras de água do município de Viçosa, MG}

O método validado foi empregado para a determinação dos trialometanos clorofórmio, bromodiclorometano, dibromoclorometano e bromofórmio; dos organoclorados aldrin, DDT, dieldrin, endossulfam, endrin, lindano, heptacloro, hexaclorobenzeno e pentaclorofenol; e dos piretroides $\lambda$-cialotrina, cipermetrina, deltametrina e permetrina; em amostras de água destinada ao consumo humano e água superficial do município de Viçosa, MG.

As amostras de água superficial não apresentaram nenhum dos 17 compostos estudados, dentro do limite de detecção do método. Já as amostras de água tratada apresentaram contaminação pelos trialometanos clorofórmio, bromodiclorometano e dibromoclorometano. Para todas as amostras analisadas os valores máximos de concentração de clorofórmio, bromodiclorometano e dibromoclorometano encontrados foram 4,$4 ; 3,8$ e $0,7 \mu \mathrm{g} \mathrm{L}^{-1}$, respectivamente. A soma da concentração dos trialometanos foi menor do que $9 \mu \mathrm{g} \mathrm{L}^{-1} \mathrm{em}$ todas as amostras analisadas, valor menor do que o LMP estabelecido pela Portaria 518 do Ministério da Saúde, que é de $100 \mu \mathrm{g} \mathrm{L}^{-1}$ para THM total. ${ }^{1}$ A presença desses compostos na amostra analisada foi confirmada por CG-EM.

Na Figura 2 é apresentado o cromatograma obtido após análise de uma amostra de água tratada. Os picos 1, 2 e 3 referem-se ao clorofórmio, bromodiclorometano e dibromoclorometano, respectivamente. Os outros picos observados no cromatograma não apresentam tempos de retenção correspondentes aos demais compostos estudados. Como esses compostos não foram detectados pelo método proposto e considerando que os LQ são menores que os LMP estabelecidos pela Portaria 518, conclui-se que as amostras analisadas atendem aos padrões de potabilidade, não oferecendo risco à saúde humana, no que diz respeito aos níveis dos 17 analitos estudados.

Para avaliação da eficiência de extração do método proposto, amostras de água superficial foram fortificadas com os analitos de interesse em concentrações próximas aos LQ obtidos para cada

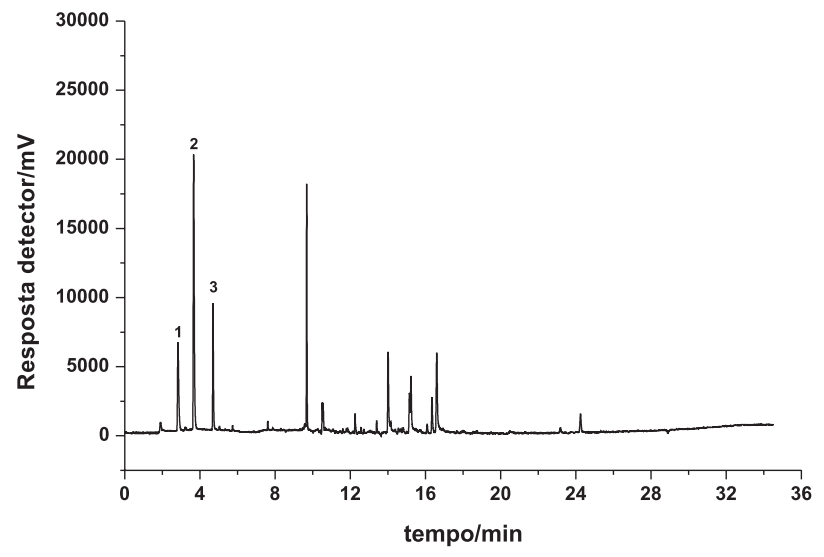

Figura 2. Cromatograma obtido da análise de amostra de água tratada do município de Viçosa, $M G$

Tabela 3. Eficiência de extração do método validado para amostra de água superficial

\begin{tabular}{|c|c|c|c|}
\hline & $\begin{array}{l}\text { Concentração } \\
\text { de fortificação } \\
\left(\mu \mathrm{g} \mathrm{L}^{-1}\right)\end{array}$ & $\begin{array}{c}\text { Concentração } \\
\text { encontrada } \\
\left(\mu \mathrm{g} \mathrm{L}^{-1}\right)\end{array}$ & $\begin{array}{l}C V^{a} \\
(\%)\end{array}$ \\
\hline \multicolumn{4}{|l|}{ Trialometanos } \\
\hline Bromodiclorometano & 1,0 & 0,7 & 7 \\
\hline Bromofórmio & 1,0 & 0,9 & 2 \\
\hline Clorofórmio & 1,0 & 1,2 & 10 \\
\hline Dibromoclorometano & 1,0 & 1,1 & 2 \\
\hline \multicolumn{4}{|l|}{ Organoclorados } \\
\hline Aldrin & 0,03 & 0,03 & 15 \\
\hline DDT & 0,1 & 0,09 & 14 \\
\hline Dieldrin & 0,03 & 0,03 & 11 \\
\hline Endossulfam & 0,1 & 0,1 & 20 \\
\hline Endrin & 0,1 & 0,1 & 7 \\
\hline Heptacloro & 0,03 & 0,03 & 14 \\
\hline Hexaclorobenzeno & 0,03 & 0,03 & 12 \\
\hline Lindano & 0,03 & 0,03 & 5 \\
\hline Pentaclorofenol & 0,1 & 0,1 & 18 \\
\hline \multicolumn{4}{|l|}{ Piretroides } \\
\hline$\lambda$-Cialotrina & 20 & 25 & 12 \\
\hline Cipermetrina & 20 & 19 & 15 \\
\hline Deltametrina & 20 & 19 & 12 \\
\hline Permetrina & 20 & 23 & 15 \\
\hline
\end{tabular}

${ }^{a}$ Coeficiente de variação $(n=3)$

composto. Os resultados de concentração obtidos para os compostos estudados foram bem semelhantes aos valores de fortificação, conforme apresentado na Tabela 3.

Os resultados obtidos indicam que o método proposto é adequado para a determinação destes compostos em amostras de água potável e superficial.

\section{CONCLUSÕES}

O método proposto apresenta boa precisão e linearidade. Os limites de quantificação para os 17 analitos de interesse atendem aos limites máximos estabelecidos pela Portaria 518 do Ministério da Saú- 
de, ${ }^{1}$ indicando a aplicabilidade do mesmo para a análise simultânea de trialometanos e dos agrotóxicos organoclorados e piretroides em água destinada ao consumo humano.

Por se tratar de um método de análise multirresíduo, não empregar solvente orgânico e exigir etapas simples de manipulação, o protocolo de análise proposto permite a análise rotineira destes compostos em águas destinadas ao consumo humano e em águas superficiais.

\section{AGRADECIMENTOS}

À FAPEMIG e ao CNPq pelo apoio financeiro. Agradecemos também aos Profs. M. X. Coutrim e R. J. de C. F. Afonso, do Departamento de Química/UFOP, pelos padrões analíticos e pelas análises realizadas no CG/EM.

\section{REFERÊNCIAS}

1. Brasil; Portaria $n^{\circ} 518$, Ministério da Saúde: Brasília, 2004.

2. Brasil; Resolução $n^{\circ}$ 357, Ministério do Meio Ambiente: Brasília, 2005.

3. Hassal, K. A.; The biochemistry \& uses of pesticides, Macmillan Press Ltd: Hong Kong, 1990.

4. Baird, C.; Química Ambiental, Bookman: Porto Alegre, 2002.

5. Brasil; Portaria $n^{o}$ 329, Ministério da Agricultura e Abastecimento: Brasília, 1985.

6. Brasil; Lei $n^{o}$ 11.936, Legislação: Brasília, 2009.

7. Santos, R. L. C. D.; Fayal, A. D. S.; Aguiar, A. E. F.; Vieira, D. B. R.; Povoa, M. M.; Rev. Saúde Pública 2007, 41, 276.

8. Hirata, R.; Quim. Nova 1995, 18, 368.

9. World Health Organization; Guidelines for Drinking-water Quality, Geneva, 2008.

10. Wang, G. - S.; Deng, Y. - C.; Lin, T. - F.; Sci. Total Environ. 2007, 387, 86.

11. Cho, D. - H.; Kong, S. - H.; Oh, S. - G.; Water Res. 2003, 37, 402.
12. Barrionuevo, W. R.; Lanças, F. M.; Quim. Nova 2001, 24, 172.

13. Casas, V.; Llompart, M.; García-Jares, C.; Cela, R.; Dagnac, T.; J. Chromatogr., A 2006, 1124, 148.

14. Junior, J. L. R.; Ré-Poppi, N.; Talanta 2007, 72, 1833.

15. Becerro-González, E.; Concha-Graña, E.; Guimarães, A.; Gonçalves, C.; Muniategui - Lorenzo, S.; J. Chromatogr., A 2007, 1141, 165.

16. Gonçalves, C.; Alpendurada, M. F.; J. Chromatogr., A 2002, 968, 177.

17. Menezes Filho, A.; Dos Santos, F. N.; Pereira, P. A. D. P.; Talanta 2010, 81,346 .

18. Instituto Nacional de Metrologia, Normalização e Qualidade Industrial (INMETRO); Orientações sobre Validação de Métodos de Ensaios Químicos, DOQ-CGCRE-008, 2003.

19. Agência Nacional de Vigilância Sanitária (ANVISA); Guia para Validação de Métodos Analíticos e Bioanalíticos, RE nº 899, de 29/05/2003.

20. United States Food and Drug Administration (US-FDA), Center for Drug Evaluation and Research, Center for Veterinary Medicine, Department of Health and Human Services; Guidance for Industry, Bioanalytical Method Validation, May, 2001.

21. International Conference on Harmonization (ICH); Validation of Analytical Procedures: Methodology, Q2B, Step 4, Consensus Guideline, 6 November 1996.

22. Mmualefe, L. C.; Torto, N.; Huntsman-Mapila, P.; Mbongwe, B.; Microchem. J. 2009, 91, 239.

23. Pawliszyn, J.; Solid-Phase Microextraction: Theory and Practice, Willey-VHC: New York, 1997.

24. Maštovská, K.; Lehotay, S. J.; J. Chromatogr., A 2004, 1040, 259.

25. Bahri, M.; Driss, M. R.; Desalination 2010, $250,414$.

26. Dong, C.; Zeng, Z.; Yang, M.; Water Res. 2005, 39, 4204.

27. Komatsu, E.; Vaz, J. M.; Quim. Nova 2004, 27, 720.

28. Sakamoto, M.; Tsutsumi, T.; J. Chromatogr., A 2004, 1028, 63.

29. Qiu, C.; Cai, M.; J. Chromatogr., A 2010, 1217, 1191. 